\title{
Root morphology of mandibular molars: a cone-beam computed tomography study
}

\author{
J. Abarca ${ }^{1,2}$, M. Duran ${ }^{3}$, D. Parra ${ }^{1 *}$, K. Steinfort ${ }^{1}$, C. Zaror ${ }^{3}$, H. Monardes ${ }^{1}$ \\ ${ }^{1}$ Endodontics Graduate Programme, Faculty of Dentistry, San Sebastian University, Santiago, Chile \\ ${ }^{2}$ Faculty of Dentistry, San Sebastian University, Puerto Montt, Chile \\ ${ }^{3}$ Centre for Research in Epidemiology, Economics and Oral Public Health (CIEESPO), Faculty of Dentistry, \\ Universidad de La Frontera, Temuco, Chile
}

[Received: 23 April 2019; Accepted: 17 July 2019]

Background: The aim of the study was to assess the number and anatomical classification of roots and root canals of first and second mandibular molars using cone-beam computed tomography (CBCT) in a Chilean population.

Materials and methods: This study evaluated the CBCT scans of 289 patients aged between 14 and 86 years, obtaining a sample of 1022 mandibular first and second molars. The number of roots and root canals was evaluated according to the anatomical classification proposed by Ahmed in 2016. Data were analysed using Pearson's chi-squared test and ANOVA.

Results: Nine hundred fifty-one (93.05\%) molars had two roots, while the remaining 71 (6.95\%) molars had one root. The most frequent root and root canal morphologies found were: ${ }^{2} M M M^{2} D^{1}$ (29.65\%), ${ }^{2} M M M^{2-1} D^{1}$ (22.3\%) and ${ }^{2} M_{M} M^{1} D^{1}$ (13.4\%) ( $M$ - mesial, D - distal), with a total of 32 different anatomical distributions. C-shaped canals were present in 56 molars and were more frequently found in women than in men (7.1\% vs. 3.88\%; $p=0.024$ ).

Conclusions: The analysis of internal anatomy using CBCT revealed a highly variable distribution of root canals. The most frequent morphology found in mandibular molars in a Chilean population was two roots and three canals. (Folia Morphol 2020; 79, 2: 327-332)

Key words: root canal configuration, mandibular molar, C-shaped canal, cone-beam computed tomography, root anatomy

\section{INTRODUCTION}

The full understanding of the external and internal dental anatomy is indispensable to successfully removing organic residue and microorganisms from root canals $[7,10]$. The correct cleaning and shaping of the main root canals could be decisive in the prognosis of the treated tooth. A study conducted by Karabucak et al. [11] shows that apical radiolucency in endodontically treated teeth appears 4 times more frequently in those with untreated root canals. Of the teeth that were observed, almost $20 \%$ of mandibular molars had untreated canals.

Mandibular molars are among the teeth that most frequently require endodontic treatment, and there are several studies that describe and analyse their complex internal anatomy. However, most of these studies have been conducted on Asian and European populations [7], there being scarce literature that

Address for correspondence: Dr. J. Abarca, Faculty of Dentistry, San Sebastian University, Lago Panguipulli 1390, Pelluco Alto, Puerto Montt, Chile, tel: +56652325536, e-mail: jaime.abarca@uss.cl

*Student of Endodontics Graduate Programme, Faculty of Dentistry, San Sebastian University, Santiago, Chile 
addresses the Latin American population [14, 19]. The influence of ethnicity on anatomical variability is known, which makes it relevant to obtain more data on the dental anatomy of Latin American and of its individual countries in particular [14]; this is because the ethnic characterisation of Latin-American countries can be quite different. For example, Brazilian population has a strong contribution of European, African, Asian and Native-American ethnic groups [5], while Chile has mainly Native-American and European genetics [15].

Internal dental anatomy studies have used different methods, which include diaphaneisation with or without staining, impressions with plastic resins, $\mathrm{X}$-rays with or without files inside the canals, retrospective evaluation of periapical $\mathrm{X}$-rays, cone-beam computed tomography (CBCT), spiral computed tomography and computed microtomography (micro-CT) $[6,7]$. The use of CBCT in anatomical studies began several years ago because it has advantages, such as the non-invasive three-dimensional (3D) analysis of structures, good resolution, adjustable field of view and low radiation dose using state-of-the-art equipment [6].

The emergence of new ways to evaluate the internal anatomy has made it difficult to use the traditional classifications of anatomy like Vertucci's [22]. The new anatomical classification proposed by Ahmed et al. [3] for dental anatomy and anomalies [1] recommends going beyond the rigidity of former classification systems and adapting to the conditions of each tooth, as well as recommending it for the 3D analysis of the dental structure.

The aim of this study was to determine the number and anatomical classification of roots and root canals of mandibular first and second molars in a Chilean population using CBCT.

\section{MATERIALS AND METHODS}

A descriptive study was carried out, prior approval of the Ethics Committee of the University San Sebastian (resolution 2019-51), where 1580 CBCT images were examined, taken as part of the diagnosis or planning of dental treatments between January 2011 and March 2015 in the Begmax Centre in Santiago, Chile. CBCT exams were included that showed mandibular first or second molars with complete root formation and root integrity of patients aged between 14 and 86 years. Teeth with endodontic treatment, open apex, signs of apical resorption or apical surgery and extensive metallic restorations that impeded the correct observation of the internal anatomy were excluded.

The CBCT images were obtained by qualified personnel using a Gendex ${ }^{\circledR}$ GXCB-500, powered by I-CAT (Gendex/Kavo Dental, GmbH, Biberach, Germany), that operates with $120 \mathrm{KVp}$ and $5 \mathrm{~mA}$, with pulsed exposure and an effective dose of 36 to $74 \mu \mathrm{Sv}$. The voxel size was $0.2 \mathrm{~mm}$ and the slice-thickness was $0.2 \mathrm{~mm}$.

Prior to the evaluation of the images, 2 observers were calibrated, first theoretically and then practically. In the practical part, each evaluator analysed ten CBCT images independently under the same conditions of time, light and screen resolution. Two weeks later the procedure was repeated under the same conditions. With the results obtained, the interobserver agreement was calculated using Cohen's Kappa coefficient, obtaining good agreement (Kappa $=0.75$ ).

The images obtained were analysed using the iCAT Vision software (Kavo Dental GmbH, Biberach, Germany) in a dark room on 19.5" LCD monitors with a resolution of $1920 \times 1080$ pixels $\left(\mathrm{LG}^{\circledR}\right)$. The samples were analysed using the three spatial axes of the programme and classifying the frequency, type of roots and root canals according to Ahmed's classification (Fig. 1) [3]. The results were collected in an Excel ${ }^{\circledast}$ spreadsheet (Microsoft Office, USA) designed specifically for this study. A descriptive analysis was performed to establish the frequency and distribution of the variables. Pearson's chi-squared test for qualitative variables and ANOVA for quantitative variables were applied for comparison between groups. For all cases a level of significance of 0.05 was considered. The results were presented through frequency distribution tables. The data were processed with the STATA 15 software (Stata Corp. LP, USA).

\section{RESULTS}

Two hundred and eighty-nine CBCT images fulfilled the inclusion criteria, with a total of 1022 molars observed. $49.61 \%$ of the CBCT images were from female patients with an average age of 30 years (range 14-86).

In terms of the frequency of roots, 951 (93.05\%) molars had two roots, whereas the remaining $71(6.95 \%)$ had one root, of which 70 were mandibular second molars (Table 1).

In terms of the distribution of roots and root canals, the most frequent was: ${ }^{2} \mathrm{MM} \mathrm{M}^{2} \mathrm{D}^{1}(29.65 \%)$, ${ }^{2} \mathrm{MM} \mathrm{M}^{2-1} \mathrm{D}^{1}$ (22.3\%) and ${ }^{2} \mathrm{MM} \mathrm{M}^{1} \mathrm{D}^{1}$ (13.4\%) (M mesial, D - distal). A third mesial canal (middle mesial 

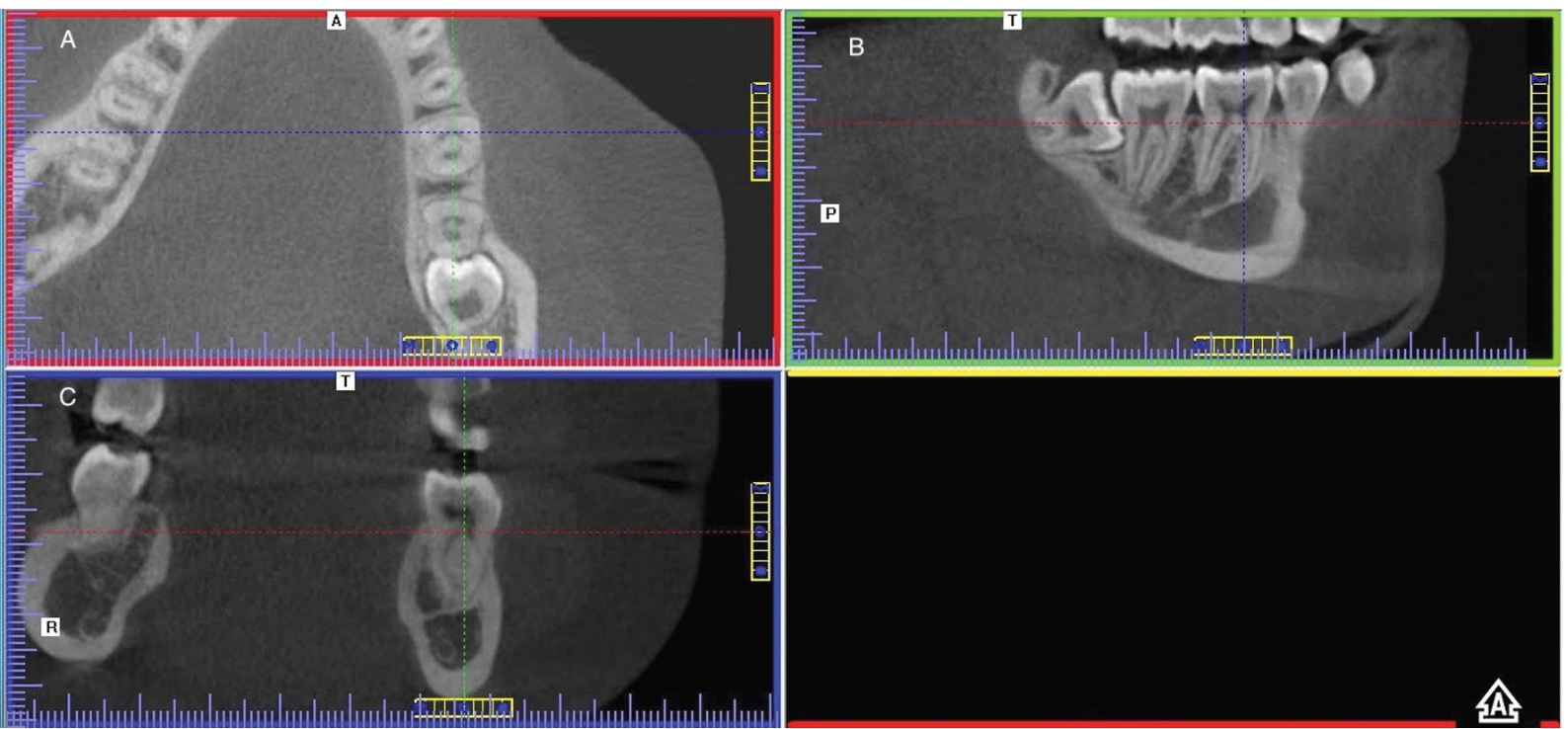

Figure 1. Cone-beam computed tomography slices (GXCB-500, powered by I-CAT, Gendex/Kavo Dental, GmbH, Biberach, Germany) used to analyse the root and root canal dental anatomy of a 46 tooth; A. Axial view, note the presence of two canals in mesial root and one canal in distal root; B. Coronal view; C. Sagittal view, where the two mesial canals are visible in their length.

Table 1. Number of roots in mandibular first and second molars

\begin{tabular}{lccc}
\hline Molars & \multicolumn{3}{c}{ Number of roots } \\
\cline { 2 - 4 } & $\mathbf{1}$ & $\mathbf{2}$ & Total \\
\hline First molars & 1 & 509 & 510 \\
Second molars & 70 & 442 & 512 \\
Total & 71 & 951 & 1022 \\
\hline
\end{tabular}

Table 2. Frequency of roots and root canals by root third in mandibular molars

\begin{tabular}{lccccc}
\hline $\begin{array}{l}\text { Number of } \\
\text { canals in } \\
\text { cervical third }\end{array}$ & \multicolumn{2}{c}{ First molar } & & \multicolumn{2}{c}{ Second molar } \\
\cline { 2 - 3 } \cline { 5 - 6 } & $\begin{array}{c}\text { Mesial } \\
\text { root }\end{array}$ & $\begin{array}{c}\text { Distal } \\
\text { root }\end{array}$ & & $\begin{array}{c}\text { Mesial } \\
\text { root }\end{array}$ & $\begin{array}{c}\text { Distal } \\
\text { root }\end{array}$ \\
\hline 0 & 0 & 0 & & 0 & 59 \\
1 & 94 & 438 & & 220 & 432 \\
2 & 416 & 72 & & 292 & 21 \\
Total & 510 & 510 & & 512 & 512 \\
\hline
\end{tabular}

canal) was present in $0.3 \%$ of the molars (Table 2 ). Thirty two different anatomical configurations were found for the roots and root canals of mandibular molars.

When referring specifically to the cervical third, it was observed that the mesial roots of the first and second molars had two canals, 416 (81.56\%) and 292 $(57.03 \%)$, respectively, unlike the distal root of the first and second molar, where only one canal was found, 438 (85.88\%) and 432 (84.37\%), respectively (Table 3). The presence of 56 molars with C-shaped canals was confirmed (Fig. 2), all in second molars, which corresponds to $11.02 \%$ of the right second molars and $12.16 \%$ of the left second molars ( $10.93 \%$ on average). This anatomical variation was found more in women than in men ( $7.1 \%$ vs. $3.88 \%)$, a difference that was statistically significant ( $p=0.024)$. No dependency ratio was found in relation to age $(p=0.156)$.

Table 3. Number of root canals in cervical third in mandibular first and second molars

\begin{tabular}{|c|c|c|c|c|c|c|}
\hline \multirow{2}{*}{$\begin{array}{l}\text { Frequency of canals } \\
\text { by root }\end{array}$} & \multicolumn{3}{|c|}{ M Root } & \multicolumn{3}{|c|}{ D Root } \\
\hline & Cervical third & Middle third & Apical third & Cervical third & Middle third & Apical third \\
\hline 0 & $0 \%$ & $0 \%$ & $0 \%$ & $5.77 \%(59)$ & $5.77 \%(59)$ & $5.58 \%(57)$ \\
\hline 1 & $30.72 \%$ (314) & $20.55 \%(210)$ & $49.51 \%(506)$ & $85.13 \%(870)$ & $86.20 \%(881)$ & $86.59 \%(885)$ \\
\hline 2 & $69.18 \%(707)$ & $79.26 \%(810)$ & $50.49 \%(516)$ & $9.10 \%(93)$ & $8.02 \%$ (82) & $7.43 \%(80)$ \\
\hline 3 & $0.1 \%(1)$ & $0.20 \%(2)$ & $0 \%$ & $0 \%$ & $0 \%$ & $0 \%$ \\
\hline
\end{tabular}




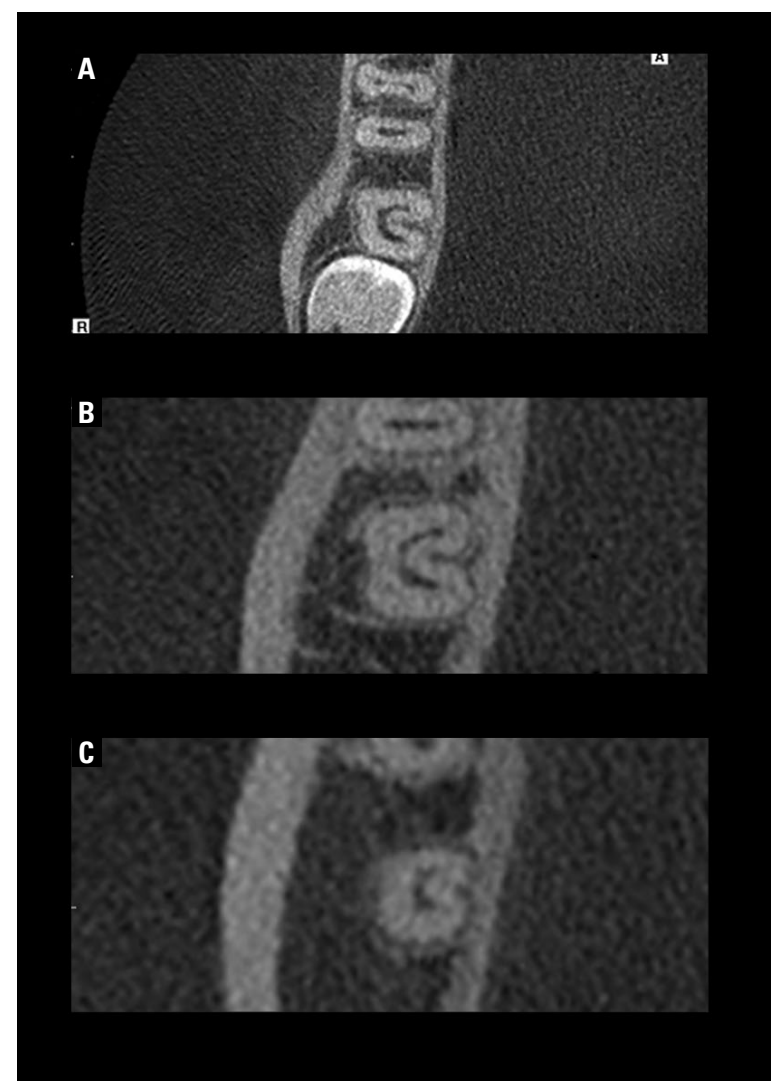

Figure 2. Cone-beam computed tomography slices (GXCB-500, powered by I-CAT, Gendex/Kavo Dental, GmbH, Biberach, Germany) used to analyse a $\mathrm{C}$-shaped mandibular second molar (arrow). Coronal view of the cervical root third (A), middle root third (B) and apical root third (C).

\section{DISCUSSION}

The different anatomical variations represent a technical challenge to achieve success in endodontic treatment [5]. Images obtained by CBCT are a reliable tool for the detection and later instrumentation of complex canal configurations [18] and one of the reasons for which their application in endodontics has increased in recent years [17].

The results obtained in this study agree with those observed in Brazilian, Palestinian, Turkish and Chinese populations, where it was seen that the most frequent morphology for mandibular molars is two canals in the mesial root and one in the distal evaluated by CBCT $[5,6,24]$. The same results were reported in Egyptian and Brazilian populations using micro-CT $[9,23]$ and in a systematic review that included 64 studies using micro-CT [18]. Evidence shows that ethnicity is more related to the number of roots than to the number or distribution of root canals [7], which would explain the similarity with the results obtained in this study.
In relation to the presence of C-shaped canals, our results are similar to those of the Belgian (8.93\%) [19] and Saudi populations (9.1\%) [4]. However, it was considerably less than what was observed in the Chinese $(29 \%)$ and Mayan populations (35\%) [14, 24]. There is some evidence that there are similarities between Native American and Northeast Asian anatomy which could explain the high incidence of $\mathrm{C}$-shaped canals in Mayan population. Differences with our results could be because Chile may have a different genetic background than North American native populations, because of European genetics due to immigration to Chile since the $18^{\text {th }}$.

Dental anatomy studies usually include a characterisation according to gender, and this is because there is some correlation between root development and the $X$ chromosome [20]. Studies conducted on Chinese and Turkish populations reported a greater prevalence of $\mathrm{C}$-shaped canals in women than in men, which is similar to what was found in this study $[4,6]$. On the other hand, Ladeira et al. [12] found no differences in the frequency of C-shaped canals according to gender in the Brazilian population. The incidence of C-shaped canals is strongly linked to ethnicity, which would explain the differences observed among the different populations $[4,7,8,12,14,24]$, but it is unknown as to why some populations present gender differences and others do not.

The third canal of the mesial root, or middle mesial canal, was first described in 1974 [22], but it has not been widely studied and presents a highly diverse prevalence among different populations, ranging from 0.1 and $22.1 \%[7,18,21]$. In this study, the presence of this third mesial canal in some of the root thirds was observed in $0.3 \%$ of cases and all converged into the mesiobuccal or mesiolingual canal, with a prevalence similar to that noted in a meta-analysis of micro-CT studies [18], but more than that observed in Brazilian (22.1\%) and Turkish (14.8\%) dental anatomy [21]. There is agreement among different studies in that the most frequent anatomical configuration of this canal is confluent [4].

Among the most frequently used methods currently to analyse internal root anatomy are CBCT and micro-CT. Both are non-invasive methods that capture 3D images of the anatomical structures [8]. The main advantage of micro-CT is the high resolution, which even allows the detailed and precise analysis of accessory structures [14]. On the other hand, the advantage of $C B C T$ is that it can be used in vivo and 
larger sample sizes can be obtained [13]. In a study by Domark et al. [8], the analysis of the two methods was compared to determine the presence of root canals in mesiobuccal roots of upper molars with no statistically significant differences being found between the two methods. Another study, however, that evaluated the configuration of mesial roots in mandibular molars, found that micro-CT showed greater detail particularly when the anatomy did not conform to Vertucci's classification [13].

Vertucci's classification [22], which has been widely used in both clinical settings and research, includes eight different types of canal configurations. The results obtained in this study show 32 different types of root and root canal configurations, which is consistent with what is proposed by Ahmed et al. [3], who suggests that the old anatomical classifications have become insufficient for the correct interpretation of 3D images like CBCT and micro-CT [9, 23]. An advantage of this new classification system is that it considers all possible root canal configurations, which in a clinical scenario, would favour a proper coronal and radicular access for the location of these canals at all levels.

Recently, its use has been proposed for research, education and clinical practice in order to gain a systematic and more precise anatomical description that facilitates endodontic treatment [2]. In our experience, this classification is more intuitive, logical and accurate in the description of internal dental anatomy.

To our knowledge, this would be the first study in molars to use this classification and it shows the reality of the diversity of root canal configurations. In a study conducted in premolars that used this new classification, they found 11 different configurations [16], which is more than what is considered by Vertucci's classification, but not as much as what was observed in this study. This may have happened because molar anatomy tends to be more complex, ranging from one to five canals per tooth.

\section{CONCLUSIONS}

The most frequent morphology found in mandibular molars in a Chilean population was two roots and three canals, two mesial and one distal. 32 different types of anatomical distribution were observed. The frequency of C-shaped canals was $10.9 \%$ in second molars.

\section{REFERENCES}

1. Ahmed HMA, Musale PK, El Shahawy OI, et al. A new system for classifying tooth, root and canal anomalies. Int Endod J. 2018; 51(4): 389-404, doi: 10.1111/iej.12867, indexed in Pubmed: 29023779.

2. Ahmed HM, Dummer PM. Advantages and applications of a new system for classifying roots and canal systems in research and clinical practice. Eur Endod J. 2018; 3(1): 9-17, doi: 10.5152/eej.2017.17064, indexed in Pubmed: 32161850.

3. Ahmed HMA, Versiani MA, De-Deus G, et al. A new system for classifying root and root canal morphology. Int Endod J. 2017; 50(8): 761-770, doi: 10.1111/iej.12685, indexed in Pubmed: 27578418.

4. Alfawaz $\mathrm{H}$, Alqedairi A, Alkhayyal AK, et al. Prevalence of C-shaped canal system in mandibular first and second molars in a Saudi population assessed via cone beam computed tomography: a retrospective study. Clin Oral Investig. 2019; 23(1): 107-112, doi: 10.1007/s00784-0182415-0, indexed in Pubmed: 29536188.

5. Caputo BV, Noro Filho GA, de Andrade Salgado DM, et al. Evaluation of the Root Canal Morphology of Molars by Using Cone-beam Computed Tomography in a Brazilian Population: Part I. J Endod. 2016; 42(11): 1604-1607, doi: 10.1016/j.joen.2016.07.026, indexed in Pubmed: 27625147.

6. Celikten B, Tufenkci P, Aksoy U, et al. Cone beam CT evaluation of mandibular molar root canal morphology in a Turkish Cypriot population. Clin Oral Investig. 2016; 20(8): 2221-2226, doi: 10.1007/s00784-016-1742-2, indexed in Pubmed: 26850623.

7. de Pablo OV, Estevez R, Péix Sánchez M, et al. Root anatomy and canal configuration of the permanent mandibular first molar: a systematic review. J Endod. 2010; 36(12): 1919-1931, doi: 10.1016/j.joen.2010.08.055, indexed in Pubmed: 21092807.

8. Domark JD, Hatton JF, Benison RP, et al. An ex vivo comparison of digital radiography and cone-beam and micro computed tomography in the detection of the number of canals in the mesiobuccal roots of maxillary molars. J Endod. 2013; 39(7): 901-905, doi: 10.1016/j. joen.2013.01.010, indexed in Pubmed: 23791260.

9. Filpo-Perez C, Bramante CM, Villas-Boas $\mathrm{MH}$, et al. Micro-computed tomographic analysis of the root canal morphology of the distal root of mandibular first molar. J Endod. 2015; 41(2): 231-236, doi: 10.1016/j. joen.2014.09.024, indexed in Pubmed: 25447505.

10. Hartmann RC, Baldasso FER, Stürmer CP, et al. Clinically relevant dimensions of 3-rooted maxillary premolars obtained via high-resolution computed tomography. J Endod. 2013; 39(12): 1639-1645, doi: 10.1016/j. joen.2013.07.029, indexed in Pubmed: 24238464.

11. Karabucak B, Bunes A, Chehoud C, et al. Prevalence of apical periodontitis in endodontically treated premolars and molars with untreated canal: a cone-beam computed tomography study. J Endod. 2016; 42(4): 538-541, doi: 10.1016/j. joen.2015.12.026, indexed in Pubmed: 26873567.

12. Ladeira DB, Cruz AD, Freitas DQ, et al. Prevalence of C-shaped root canal in a Brazilian subpopulation: a cone- 
beam computed tomography analysis. Braz Oral Res. 2014; 28: 39-45, doi: 10.1590/s1806-83242013005000027, indexed in Pubmed: 25000603.

13. Ordinola-Zapata $R$, Bramante $C M$, Versiani $M A$, et al. Comparative accuracy of the Clearing Technique, CBCT and Micro-CT methods in studying the mesial root canal configuration of mandibular first molars. Int Endod J. 2017; 50(1): 90-96, doi: 10.1111/iej.12593, indexed in Pubmed: 26659613.

14. Ramírez-Salomón $\mathrm{M}$, Vega-Lizama $\mathrm{E}$, Tiesler $\mathrm{V}$, et al. The $C$-shaped canal molar: an Endodontic-Archaeological study of the relationships between Mayan pre-Hispanic and contemporary population of Yucatán. Int Endod J. 2014; 47(11): 1084-1089, doi: 10.1111/iej.12255, indexed in Pubmed: 24471812.

15. Rocco PP, Morales CG, Moraga MV, et al. Composición genética de la población chilena: Distribución de polimorfismos de DNA mitocondrial en grupos originarios y en la población mixta de Santiago. Revista médica de Chile. 2002; 130(2): 125-131, doi: 10.4067/s003498872002000200001.

16. Saber SEDM, Ahmed MHM, Obeid M, et al. Root and canal morphology of maxillary premolar teeth in an Egyptian subpopulation using two classification systems: a cone beam computed tomography study. Int Endod J. 2019; 52(3): 267-278, doi: 10.1111/iej.13016, indexed in Pubmed: 30225932.

17. Setzer FC, Hinckley N, Kohli MR, et al. A survey of cone-beam computed tomographic use among endodontic practitioners in the united states. J Endod. 2017; 43(5): 699-704, doi: 10.1016/j.joen.2016.12.021, indexed in Pubmed: 28292601.

18. Tomaszewska IM, Skinningsrud B, Jarzębska A, et al. Internal and external morphology of mandibular molars:
An original micro-CT study and meta-analysis with review of implications for endodontic therapy. Clin Anat. 2018; 31(6): 797-811, doi: 10.1002/ca.23080, indexed in Pubmed: 29577434.

19. Torres $A$, Jacobs $R$, Lambrechts $P$, et al. Characterization of mandibular molar root and canal morphology using cone beam computed tomography and its variability in Belgian and Chilean population samples. Imaging Sci Dent. 2015; 45(2): 95-101, doi: 10.5624/isd.2015.45.2.95, indexed in Pubmed: 26125004.

20. Varrela J. Effect of $45, X / 46, X X$ mosaicism on root morphology of mandibular premolars. J Dental Res. 2016; 71(9): 1604-1606, doi: 10.1177/00220345920710091101, indexed in Pubmed: 1522293.

21. Versiani MA, Ordinola-Zapata R, Keleş $A$, et al. Middle mesial canals in mandibular first molars: $A$ micro-CT study in different populations. Arch Oral Biol. 2016; 61: 130-137, doi: 10.1016/j.archoralbio.2015.10.020, indexed in Pubmed: 26556548.

22. Vertucci F. Root canal morphology and its relationship to endodontic procedures. Endodontic Topics. 2005; 10(1): 3-29, doi: 10.1111/j.1601-1546.2005.00129.x.

23. Wolf TG, Paqué $F$, Zeller $M$, et al. Root canal morphology and configuration of 118 mandibular first molars by means of micro-computed tomography: an ex vivo study. J Endod. 2016; 42(4): 610-614, doi: 10.1016/j. joen.2016.01.004, indexed in Pubmed: 26906239.

24. Zhang $R$, Wang $H$, Tian $Y Y$, et al. Use of cone-beam computed tomography to evaluate root and canal morphology of mandibular molars in Chinese individuals. Int Endod J. 2011; 44(11): 990-999, doi: 10.1111/j.13652591.2011.01904.x, indexed in Pubmed: 21658074. 